Original Research Paper

\title{
Reduction of Microbial Contamination of Outlet Waste in Urban Wastewater Treatment Plants
}

\author{
${ }^{1}$ Sona Pazdar, ${ }^{2}$ Saeid Eslamian, ${ }^{3}$ Hossein Gholami and ${ }^{4}$ Kaveh Ostad-Ali-Askari \\ ${ }^{I}$ Department of Civil Engineering, Aghigh University, Shahinshahr, Isfahan, Iran \\ ${ }^{2}$ Department of Water Engineering, College of Agriculture, Isfahan University of Technology, Isfahan, Iran \\ ${ }^{3}$ Department of Civil Engineering, Isfahan (Khorasgan) Branch, Islamic Azad University, Isfahan, Iran \\ ${ }^{4}$ Department of Civil Engineering, Najafabad Branch, Islamic Azad University, Najafabad, Iran
}

\author{
Article history \\ Received: 22-10-2018 \\ Revised: 29-03-2019 \\ Accepted: 16-09-2019 \\ Corresponding Author: \\ Sona Pazdar \\ Department of Civil Engineering, \\ Aghigh University, Shahinshahr, \\ Isfahan, Iran \\ Email: \\ sona.pazdar2011@gmail.com
}

\begin{abstract}
The available research was managed to monitor the physicochemical and microbiological features of treatment plants. The wastewater treatment herb sewage is a straight pollution input source for anthropogenic pollution. The sediment information ideas to an urban drainage trench as a secondary point pollution source while the organotins information highlights the presence of other spread sources, special to this material. wastewater re-use in urban has increased in many realms. The consequences of the study display that among the offered treatments, the best for asepsis and reducing microbial pollution of urban outlet effluent is that of the plus 0.25 weight percent Permanganate filter. Due to the amount of demand and need for the use of wastewater and circulated waters in agriculture, now most of wastewater treatment plants in the IRAN are designed and administered with the goal of reusing the wastewater produced in agriculture. Using wastewater increases the functioning of plants and does not have negative effects on the properties of the soil and its permeability. At the time in numerous cities of the IRAN the urban sewage and surface runoff which leave the cities, are used in farms downstream. The best option for the microbial disinfecting of the outlet wastewater in urban wastewater treatment plants among the treatments presented belonged to the plus 0.25 weight percent of potassium permanganate powder filter treatment. So that the percentage of the elimination of microbial pollution reached more than $99.99 \%$ Using this treatment in urban wastewater treatment plants can increase the microbial quality of wastewater to very high values, which can be utilized in farms, nutrition of groundwater resources, entrance to surface waters, Irrigating the green space, use in car-washes, etc.
\end{abstract}

Keywords: Wastewater, Microbial Pollution, Filter, Sewage Treatment, Potassium Permanganate, Chahar Tokhm (Expectorant) Powder

\section{Introduction}

The development of the application of sewage is the lack of water needed for agriculture. The high cost of advanced sewage treatment processes, the recognition of nutritive elements presents in sewage and the positive effect of sewage in increasing agricultural production. Although irrigation with wastewater is a source of beneficial effects, if its destructive effects are not controlled and managed, the harmful effects outweigh its beneficial effects. In addition, there is little data on the effects of this kind of irrigation on the physical and chemical properties of the soil and the quality of the outlet of one factory is different than of another and therefore are its effects (Brown, 2019). It is time that an affordable and accessible method for all places and conditions of wastewater treatment be brought into consideration and that is no method other than using a system of sand filtration as a natural treatment filter instead of costly pools. The sufficient quality and quantity of water is essential for the survival of mankind. The primitive man understood the great importance of water. So, civilizations were created around sources of water, so that in addition to providing the vital needs, 
they would be able to eliminate agricultural and transportation needs. The treatment of city sewage, in addition to protecting the environment, causes the utilization of sewage, extraction and recovery of the utilized water. Especially in crowded urban areas in which the lion's share of the present water is consumed, this matter is of the greatest concern (Ballesté and Blanch, 2010). Today because of the shortage of accessible water sources, especially for agriculture, reusing the sewage in addition to stopping the pollution of water sources, causes many of the problems of water shortage to be resolved. Also, the achieving of sufficient water resources and effective and affordable elimination of disease factors, chemicals and other pollutions is a growing universal challenge. Although the common procedure of water treatment which includes coagulation, flaking, sedimentation and smoothing, eliminates most of the microorganisms in most cases, because of the remaining of some microorganisms or their ingression after these procedures, it is necessary to disinfect the water (Manaia et al., 2010). One of the indicators used by the World Health Organization for reusing wastewater is the counting of coliforms in wastewater which can be used as a Criterion of health and safeness in utilizing wastewater (Gómez et al., 2016). These bacteria can be dealt with through disinfection. There are many methods for disinfection which fall into two general categories of physical and chemical methods. Of the common chemical procedures, chlorination and using ozone gas and of the common physical procedures, heating, filtration and irradiation can be mentioned (European Economic Community Council, 1991).

The ever-increasing population, the pollution of underground and surface waters, the uneven distribution of water resources and periodical drought, has forced water supplying organizations to look for new resources of water. Utilizing the treated wastewater that is discharged from sewage treatment plants into the environment, has gained more attention as a reliable source (McConnell et al., 2018). Today in many countries the use of treated wastewater and reusing water is an important point in managing water resources. The efficient use of present water resources, the development of new resources and the saving of water are of the most important options that should be considered in supplying water resources. For the study of the decrease in the general number of coliforms in the outlet water of wastewater treatment plants and the evaluation of the quality of wastewater by each natural and chemical additive that was used in this article, the intended studies took place. The present research took place in the urban wastewater treatment plant located in the city of Aligoodarz in Sanj village road in the spring and summer of 2016. In the wastewater treatment plants of Aligoodarz, wastewater enters the plant at 70 liters per second. For the purpose of this study, the outlet water of the wastewater treatment plant was used whose properties are presented in Table 1 (Castro-Hermida et al., 2008).

Ozonated liquid is mixed within a multi-step clarifier organization with wastewater to be preserved and indistinct solids are removed (Kulkarni et al., 2018). The elucidated effluent is filtered and revealed to ultraviolet radiation. Ozone is injected into the irradiated wastewater and received within a contact tower where the reaction between the pollutants and ozone happens. The ultraviolet irradiated, ozonated and elucidated fluid is recirculated through an ozone injector and discharged through a mixer plate into a purge chamber (ISO, AENOR, 2001). The purgative chamber sewage is split, with a portion returning to the contact tower and passing through a second ultraviolet radiation source and the remaining purge chamber effluent being distributed within the clarifiers. After a programmed residence within the system, a diverter valve in the return line is operable to discharge the treated water through a carbon filter and out of the system. The recirculation of the UV irradiated ozonated liquid provides both effective solids elimination and feedback of the contaminants with the ozone to produce suitable treated water (Control del Estado de las Masas de Agua, 2015).

Table 1 shows the amount of the parameter which is beneficial for wastewater, for example, one of the importance of them is coliform focal equals 46000 (MPN/100 mL) and PH is 7/3 (5/6-9), TDS is 578 less than 1500 then it is suitable. Total coliforms include bacteria that are found in the soil, in water that has been influenced by surface water and in human or animal waste (ISO, AENOR, 2008). Fecal coliforms are the group of the total coliforms that are considered to be present specifically in the gut and feces of warm-blooded animals. Because the origins of fecal coliforms are more specific than the origins of the more general total coliform group of bacteria, fecal coliforms are considered a more accurate indication of animal or human waste than the total coliforms (ISO, AENOR, 2014).

Figure 1 shows the City of Aligoodarz Wastewater Treatment Plant serves the needs of the City of Aligoodarz. The procedure utilizes physical, chemical and biological processes and produces an environmentally safe fluid waste stream (treated effluent) and a solid waste appropriate for disposal or reuse (ISO, AENOR, 2013).

Table 1: Some properties of the utilized sewage

\begin{tabular}{llllll}
\hline Parameter & $\begin{array}{l}\text { Coliform focal } \\
\text { (MPN/100 mL) }\end{array}$ & $\begin{array}{l}\text { Total coliform } \\
\text { (MPN/100 mL) }\end{array}$ & $\begin{array}{l}\text { Opacity } \\
(\text { NTU) }\end{array}$ & $\begin{array}{l}\text { Dissolved solids } \\
\text { in total TDS (mg/lit) }\end{array}$ & PH \\
\hline Amount & 46000 & 240000 & 180 & 578 & $7 / 3$ \\
\hline
\end{tabular}




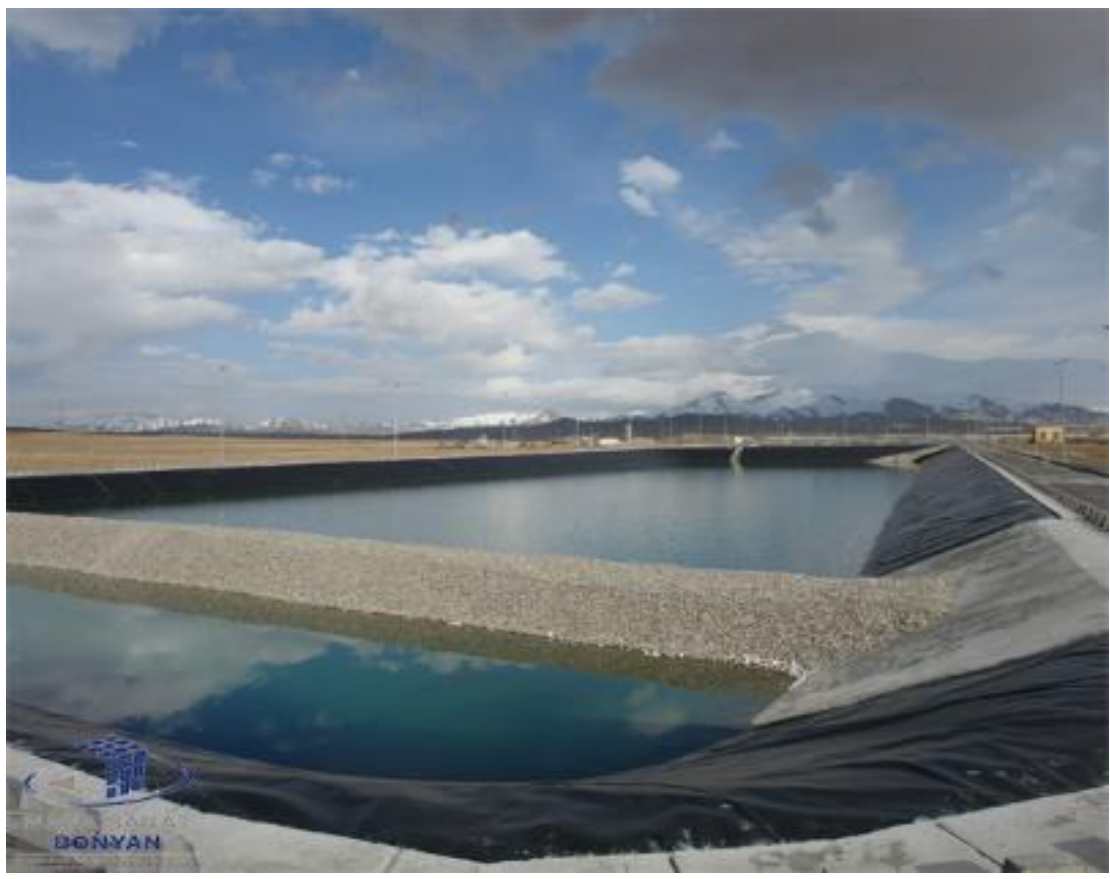

Fig. 1: The wastewater treatment system of the city of Aligoodarz

\section{Results}

The general coliform and focal coliform have decreased significantly. The elimination efficiency (percent) of its equation is as below:

$$
\begin{aligned}
& \text { Elimination efficiency }(\text { percent }) \\
& =\frac{\left(\begin{array}{l}
\text { Number of filters after coliform } \\
- \text { Number of filters after coliform }
\end{array}\right)}{(\text { Number of filters before coliform })}
\end{aligned}
$$

\section{Experimental}

Irrigation is a great use for sewage effluent because it is mainly water with nutrients. For small flows, the wastewater can be applied on particular, well-supervised "sewage grounds," where forage, fiber, or seed crops are got bigger that can be irrigated with usual primary or secondary wastewater (Naidoo and Olaniran, 2014). Large-scale use of the wastewater needs special treatment so that it meets the public health, agronomic and aesthetic demands for unlimited use (no contrary effects on crops, soils, humans and animals). Most administration standards consider only with public health aspects and prescribe the treatment processes or the quality parameters that the wastewater must meet before it can be applied to irrigate a specified category of crops (Ishii, 2008). However, agriculture perspectives related to crops and soils must also be taken into account. Quality parameters to be assessed consist bacteria, viruses and other pathogens; total salt content and sodium adsorption ratio of the water (soil as well as crop effects); nitrogen; phosphorus; chloride and chlorine; bicarbonate; heavy metals, boron and other trace elements; $\mathrm{pH}$; and synthetic organics (including pesticides) (Garcia-Armisen et al., 2011).

The investigation displays the significance of stable monitoring of pollution to attain an sufficient inhibition policy. In universal there is a orientation to recovery on this coast, ascribable to a better sewage disposal network. Ozonated fluid is blended within a multi-step clarifier method with wastewater to be treated and indistinct solids are deleted. The elucidate wastewater is filtered and reveal to ultraviolet radiation (Mohammed et al., 2012). Ozone is introduced into the irradiated wastewater and acquired within a contact tower where response between the pollutants and ozone takes place. The ultraviolet irradiated, ozonated and purified fluid is recirculated through an ozone injector and separate through a mixer plate into a purge chamber (George et al., 2002). The purge chamber wastewater is gap, with a contribution returning to the contact tower and passing through a second ultraviolet radiation source and the residual purge chamber wastewater being spread within the clarifiers. After a predestine residence within the process, a diverter valve in the reversal line is treatable to discharge the behaved water through a carbon filter and out of the process (Orruño et al., 2017). The recirculation of the UV irradiated ozonated fluid prepares both impressive solids elimination and 
response of the pollutants with the ozone to generate an admissible treated water. The consequnces show the attendance of anthropogenic contaminant all along the investigation attain. The effluent treatment plant wastewater is a direct contamination input source for anthropogenic contamination (Lanao et al., 2010).

Removal performances for bacteria and several chemical compnents were more exterior during the primary year contrasted to the second year of action, offering concern for long-term performance and consistency of such wastewaters (Orruño et al., 2014). Microalgae increase the elimination of nutrients, organic pollutants, heavy metals and pathogens from domestic effluent and furnish an interesting raw substance for the generation of high-value chemicals (algae metabolites) or biogas. Photosynthetic oxygen production also decreases the require for external aeration, which is especially benefits for the treatment of perilous contaminations that must be biodegraded aerobically but might volatilize during mechanical aeration (Chen et al., 2017).

Lake bottom sediments were prepared and inspected for grain size, organic matter, organic carbon, nitrogen, phosphorus, heavy metals and hydrophobic organic compounds to assess their condensation and spatial dispensation. contaminant condensations are still high and the cumulation of contaminants may show a considerable source of toxicity for benthic organisms (Nguyen et al., 2012). It deuceds that pollutant diminution at the source will be essential for a further betterment. In the watercourse, no self-cleaning results could be noticed. Small dense treatment plants discharge demeaned effluent with a poor microbiological modality contrasted to urban water modality and the modality of treated effluent of larger herbs. During storm water incidents, condensations of microorganisms downstream of sewer overflows were almost two logs higher than during dry weather situations. Condensations of parasites reduced slowly during the overflow, in parallel to filterable matter and particle-bound materials (Marín et al., 2015). The annual load of microorganisms emanated from CSOs notably invades the load from demeaned wastewater of the wastewater herbs. Thus, an improved hygienic modality of the water path could be attained by hindering overflows and by increasing sewage intervention herbs (López, 2013).

To assesses if the soil and the aquifer underneath are influenced by the benefit of this kind of water, speimens should take along a period of several months from the effluent treatment heb, the consolidation lagoon, groundwater and soil profiles. Analyses should execute for total coliforms and aerobic bacteria, soil water pressure and soil water content as well as chemical examinations of the irrigation water, aquifer and water of the urban area. Sludge re-use in urban has enhanced in many countries, but this process must be associated with a science of the pathogens available in these muds (Madoux-Humery et al., 2013).

Using Equation (1), the elimination efficiency for the general coliform and focal coliform in respect are 80/8 and $90 \%$. Although this is a significant efficiency and the filter as a medium for wastewater can be counted as very efficient in decreasing microbial contamination, the contamination level of the sample wastewater, still has a great distance to the instruction in the method standard which has values of 1000 MPN/100 mL for total coliform and $400 \mathrm{MPN} / 100 \mathrm{~mL}$ for focal coliform at maximum (Naidoo and Olaniran, 2014). Alcalde and co-researchers concluded that the sand filter plays an effective role as a complex refinement process in decreasing the population of microorganisms in the index. In advanced wastewater treatment with sand filters for agricultural use in the country of Kuwait, the number of coliforms was decreased to 2 MPN/100 mL. Yore and coworkers observed in their research that as the treated wastewater passes through unsaturated parts of the sand, viruses and fecal coliforms are eliminated completely (Madigan et al., 2009). Hence the results of this part are in accord with the research done. manufactured wetlands are among the lately demonstrated impressive technologies for wastewater treatment. Compared to conventional treatment systems, constructed wetlands are low cost, are easily used and retained and have a strong potential for application in developing countries, individually by small villages associations. but these methods have not established widespread use, due to lack of knowledge and local expertise in expanding the technology on a local basis (Lépesová et al., 2018).

A clear picture of the quality of the treated wastewater and calculated values are presented in Table 3 . Note that these values are the result of the best conditions and the highest efficiency (Mosteo, 2013). The standard table of environmental criteria for quality can be seen further in the text. Noting the water shortage crisis and the cost of improving water resources and its refinement in the country, the wastewater of urban sewage treatment can be utilized for urban and non-urban uses and its kind depends on the quantity and quality of the raw sewage, the needed refinement degree, refinement cost and the nature of environmental rules and standards. Biological contamination is one of the most important concerns of utilizing wastewater in irrigation (Madoux-Humery et al., 2013). Generally, in most presented standards for after the secondary refinement, disinfection comes as a supplementary process which results in the usage of sewage wastewater in the irrigation of food products and parks. It is clear that high densities of Nitrogen and Phosphorus is beneficial for the growth of plants and can be a good substitute for chemical fertilizers (Lucas et al., 2014). 


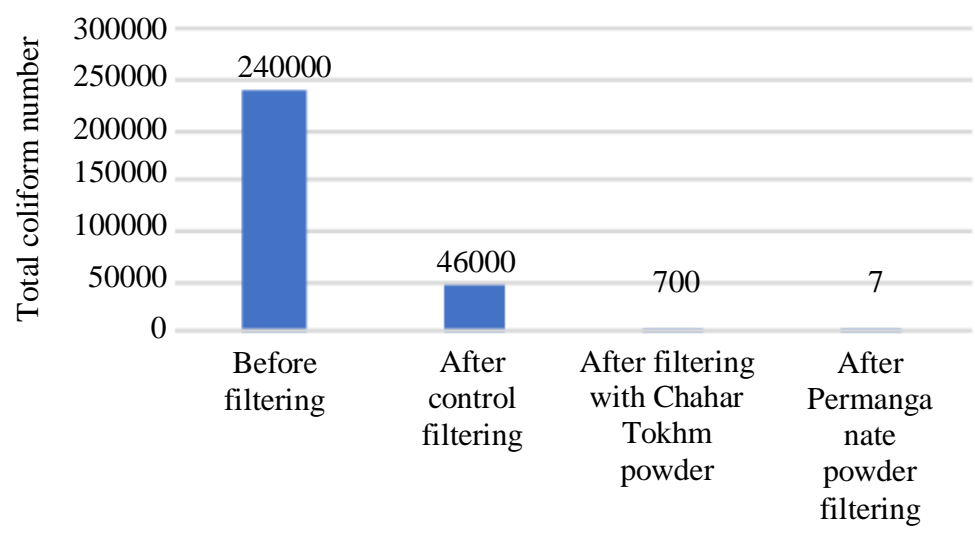

Fig. 2: Comparison of total Number of Coliforms (Horizontal Axes: Wastewater sample before filtering, Wastewater sample after control filtering, Wastewater sample after filtering with Chahar Tokhm powder, Wastewater sample after Permanganate powder filtering)

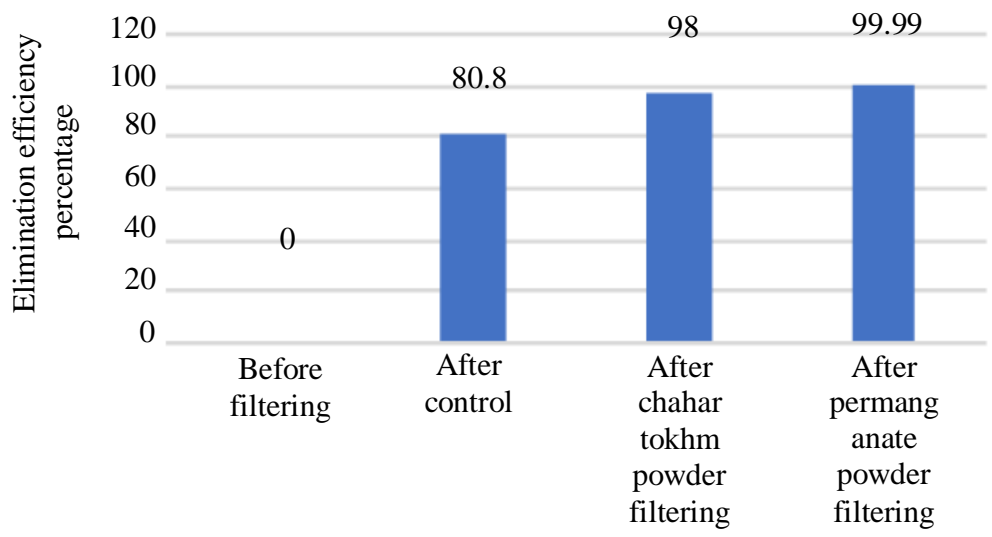

Fig. 3: Comparison of the Efficiency of total Coliforms Elimination (Horizontal Axes: Wastewater sample before filtering, Wastewater sample after control filtering, Wastewater sample after filtering with Chahar Tokhm powder, Wastewater sample after Permanganate powder filtering)

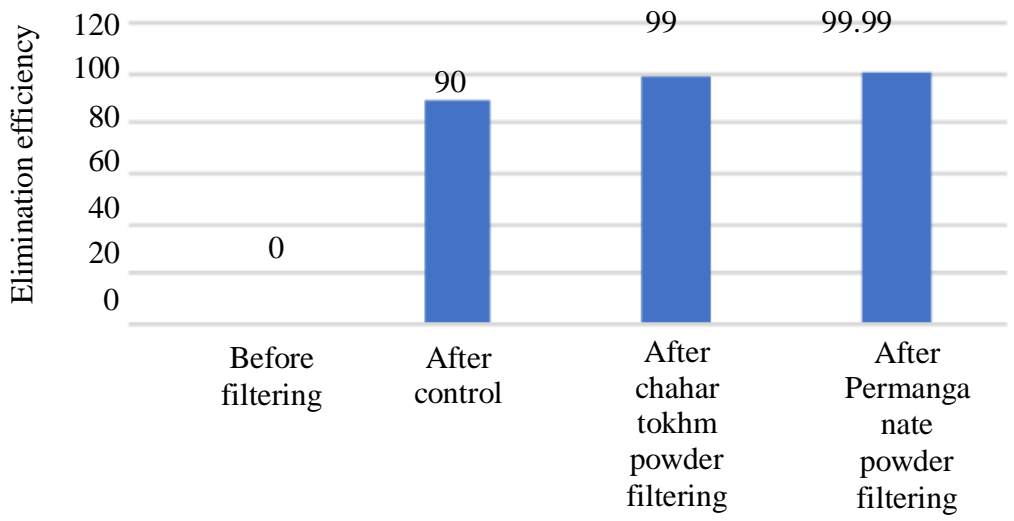

Fig. 4: Comparison of the Efficiency of fecal Coliforms Elimination (Horizontal Axes: Wastewater sample before filtering, Wastewater sample after control filtering, Wastewater sample after filtering with Chahar Tokhm powder, Wastewater sample after Permanganate powder filtering) 
Table 2: General results of the study in all phases

\begin{tabular}{lllr}
\hline Contaminators & Discharge of surface waters & Drain into absorbent well & Agricultural and Irrigation uses \\
\hline Total coliforms $M P N / 100 m L$ & 1000 & 1000 & 1000 \\
Fecal coliforms MPN/100 mL & 400 & 400 & 400 \\
Opacity NTU & 50 & - & 50 \\
\hline
\end{tabular}

Table 3: Urban wastewater quality standard

\begin{tabular}{llll}
\hline Parameter & Control filter & Filter + Chahar Tokhm powder & Filter + Permanganate powder \\
\hline Total coliform $M P N / 100 \mathrm{~mL}$ & 46000 & 700 & 7 \\
Fecal coliform $M P N / 100 \mathrm{~mL}$ & 4600 & 400 & 0 \\
Opacity $N T U$ & 60 & - & 8 \\
\hline
\end{tabular}

Figure 2 shows the highest amount of wastewater depend on the total coliform number is 240000 and the lowest is 7. But Fig. 3 shows the elimination efficiency percentage is $99.99 \%$ that is the highest percentage but the lowest percentage is 0 and Fig. 4 is the same as Fig. 4.

Table 2 shows Public consequences of the investigation in all stages. It considers three various stages (Total coliform, Fecal coliform and Opacity NTU) which there are diverse amount of pollution. But every stage almost has an equal result for example Discharge of surface waters, Drain into absorbent well, Agricultural and Irrigation uses equal 1000,1000 and 1000 (MPN/100 mL), respectively.

\section{Discussion}

The goal of the present study was to evaluate the effect of this measure. However, pollutants condensations are still great and the accumulation of pollutants may demonstrate a significant source of toxicity in urbanization. One concludes that pollutant reduction at the source will be essential for further recovery. The consequences disclosed that high-grade floating contamination existed at several sites. The biological parameters counted had no obvious correlation with meteorological parts such as temperature, relative humidity or wind features. Viral contamination demonstrated to be entirely wide-spread and noticeable even in the existence of low levels of bacterial contamination. Municipal solid waste disposal has become an ever-increasing issue in IRAN towns, partially due to the dominant rapid urbanization development. But, this exercise has caused a variety of environmental and public health issues.

The results of the study show that among the presented treatments, the best for disinfection and decreasing microbial contamination of urban outlet wastewater is that of the plus 0.25 weight percent Permanganate filter. As the percentage of contamination elimination reached 99.99 whilst applying this method. The reason for this is the oxidizing and disinfectant properties of potassium permanganate powder which can deactivate all coliforms. In fact, it can be stated that the oxidation and filtration system is performed simultaneously and as an oxidizing agent with a direct oxidation mechanism of the cellular body and this property, in addition to eliminating microbial contamination, causes the chance of Permanganate mixing with chemicals in the wastewater such as Iron and Manganese which would oxidize and precipitate to be eliminated.

\section{Discussion}

The results for decreasing fecal coliforms are in the same way and adding Permanganate powder to the filter in the treatment showed significant returns so that no digestive microbial contamination was found in this phase. For the opacity parameter, the filter with potassium permanganate powder had more removal efficiency than the control filter $(95 \%)$. The advantages of this material include the lack of production of lateral products, easy transportation, storage and use. Therefore, the results of this study indicate the acceptable efficiency of this method in reducing microbial load, in a way that due to its high efficiency, low cost and no need for special forces, the use of this method is able to provide reuse for reuse in various uses, such as irrigation of agricultural land, nutrition of groundwater, aquaculture, use in carwashes.

\section{Conclusion}

The sanitary landfills knowledge is original in the country and is anticipated to prepare explanations to some of the existing issues. Instead, if the method will be misused, which is likely judging from the existing inclinations, far-reaching environmental implications could result. The occurrence of wastewater in the environment has become an increasing public concern as new environmental monitoring activities disclose the attendance of a broad range of continuous pharmaceuticals in soil and water. Articles display that municipal wastewater treatment herbs are significant to point originals of antibiotics and antibiotic-immune bacteria in the environment. 


\section{Author's Contributions}

All authors contributed to design the study, write and revise the manuscript.

\section{Ethics}

The present study was approved by the Isfahan University of Technology.

\section{References}

Ballesté, E. and A.R. Blanch, 2010. Persistence of bacteroides species populations in a river as measured by molecular and culture techniques. Appl. Environ. Microb., 76: 7608-7616.

Brown, P.C., E. Borowska, T. Schwartz and H. Horn, 2019. Impact of the particulate matter from wastewater discharge on the abundance of antibiotic resistance genes and facultative pathogenic bacteria in downstream river sediments. Sci. Total Environ., 649: 1171-1178.

Castro-Hermida, J.A., I. García-Presedo, A. Almeida, M. González-Warleta and J.M.C. Da Costa et al., 2008. Contribution of treated wastewater to the contamination of recreational river areas with Cryptosporidium spp. and Giardia duodenalis. Water Res., 42: 3528-3538.

Chen, Y., S. Lan, L. Wang, S. Dong and H. Zhou et al., 2017. A review: Driving factors and regulation strategies of microbial community structure and dynamics in wastewater treatment systems. Chemosphere, 174: 173-182.

Control del Estado de las Masas de Agua (CEMAS), 2015. Confederación Hidrográfica del Ebro. http://195.55.247.234/webcalidad/cemas/informes/2 014_2015_cemas/05_zonas_protegi das.pdf (Website, last date accessed 28/06/2019)

European Economic Community Council, 1991. 91/271/EEC of 21 May 1991 concerning urban waste-water treatment. EEC Counc. Dir.

Garcia-Armisen, T., K. Vercammen, J. Passerat, D. Triest and P. Servais et al., 2011. Antimicrobial resistance of heterotrophic bacteria in sewagecontaminated rivers. Water Res., 45: 788-96.

George, I., P. Crop and P. Servais, 2002. Faecal coliform removal in wastewater treatment plants studied by plate counts and enzymatic methods. Water Res., 36: 2607-2617.

Gómez, P., C. Lozano, D. Benito, V. Estepa and C. Tenorio et al., 2016. Characterization of staphylococci in urban wastewater treatment plants in Spain, with detection of methicillin resistant Staphylococcus aureus ST398. Environ. Pollut., 212: 71-76.
Ishii, S. and M.J. Sadowsky, 2008. Escherichia coli in the Environment: implications for water quality and human health. Microbes Environ., 23: 101-108.

ISO, AENOR, 2001. UNE EN ISO 78992:2001.Calidad del agua. Detección y recuento de enterococos intestinales. Parte 2: Método de filtración de membrana.

ISO, AENOR, 2008. UNE EN ISO 16266:2008.Calidad del agua. Detección y recuento de Pseudomonas aeruginosa. Método por filtración en membrana.

ISO, AENOR, 2013. UN-EN ISO 5667-3:2013 Calidad del agua. Muestreo. Parte 3: Conservación y manipulación de las muestras de agua.

ISO, AENOR, 2014. UNE EN ISO 9308-1:2001.Calidad del agua. Detección y recuento de Escherichia coli y de bacterias coliformes. Parte 1: Método de filtración en membrana.

Kulkarni, P., Olson, N.D., Paulson, J.N., Pop, M., Maddox, C., Claye, E., Rosenberg Goldstein, R.E., Sharma, M., Gibbs, S.G., Mongodin, E.F., Sapkota, A.R. Conventional wastewater treatment and reuse site practices modify bacterial community structure but do not eliminate some opportunistic pathogens in reclaimed water. Sci. Total Environ., 639 (2018), 1126-1137.

Lanao, M., M.P. Ormad, P. Goñi, N. Miguel and R. Mosteo et al., 2010. Inactivation of Clostridium perfringens spores and vegetative cells by photolysis and $\mathrm{TiO} 2$ photocatalysis with $\mathrm{H} 2 \mathrm{O} 2$. Sol. Energy, 84: 703-709.

Lépesová, K., L. Kraková, D. Pangallo, A. Medvedová and P. Olejníková et al., 2018. Prevalence of antibiotic-resistant coliform bacteria, Enterococcus spp. and Staphylococcus spp. in wastewater sewerage biofilm. J. Glob. Antimicrob. Re., 14: 145-151.

López, A., 2013. Análisis de la calidad de las aguas superficiales destinadas a abastecimiento humano de la cuenca del Ebro, utilizando diversas metodologías de diagnóstico. Doctoral Thesis. University of Zaragoza.

Lucas, F.S., C. Therial, A. Gonçalves, P. Servais and V. Rocher et al., 2014. Variation of raw wastewater microbiological quality in dry and wet weather conditions. Environ. Sci. Pollut. Res. Int., 21: 5318-28.

Madigan, M.T., J.M. Martinki, P.V. Dunlap and D.P. Clark, 2009. Brock: Biología de los microorganismos. 12nd Edn., Pearson Education. Madrid (España).

Madoux-Humery, A.S., S. Dorner, S. Sauvé, K. Aboulfadl and M. Galarneau et al., 2013. Temporal variability of combined sewer overflow contaminants: Evaluation of wastewater micropollutants as tracers of fecal contamination. Water Res., 47: 4370-4382. 
Manaia, C.M., A. Novo, B. Coelho and O.C. Nunes, 2010. Ciprofloxacin resistance in domestic wastewater treatment plants. Water. Air. Soil Pollut., 208: 335-343.

Marín, I., P. Goñi, A.M. Lasheras and M.P. Ormad, 2015. Efficiency of a Spanish wastewater treatment plant for removal potentially pathogens: Characterization of bacteria and protozoa along water and sludge treatment lines. Ecol. Eng.,. 74: 28-32.

McConnell, M.M., L.T. Hansen, R.C. Jamieson, K.D. Neudorf and C.K. Yost et al., 2018. Removal of antibiotic resitance genes in two tertiary level municipal wastewater treatment plants. Sci Total Environ., 643: 292-300.

Mohammed, R.L., A. Echeverry, C.M. Stinson, M. Green and T.D. Bonilla et al., 2012. Survival trends of Staphylococcus aureus, Pseudomonas aeruginosa, and Clostridium perfringens in a sandy South Florida beach. Mar. Pollut. Bull., 64: 1201-1209.

Mosteo, R., M.P. Ormad, P. Goñi, J. Rodríguez-Chueca and A. García et al., 2013. Identification of pathogen bacteria and protozoa in treated urban wastewaters discharged in the Ebro River (Spain): Water reuse possibilities. Water Sci. Technol., 68: 575-583.
Naidoo, S. and A.O. Olaniran, 2014. Treated wastewater effluent as a source of microbial pollution of surface water resources. Int. J. Environ. Res. Public Health, 11: 249-270.

Nguyen, H.T.M., Q.T.P. Le, J. Garnier, J.L. Janeau, and E. Rochelle-Newall et al., 2012. Seasonal variability of faecal indicator bacteria numbers and die-off rates in the Red River basin, North Viet Nam. Scientific Reports, 6: 21644.

Orruño, M., I. Garaizabal, Z. Bravo, C. Parada and I. Barcina et al., 2014. Mechanisms involved in Escherichia coli and Serratia marcescens removal during activated sludge wastewater treatment. Microbiologyopen, 3: 657-667.

Orruño, M., V.R. Kaberdin and I. Arana, 2017. Survival strategies of Escherichia coli and Vibrio spp.: contribution of the viable but nonculturable phenotype to their stressresistance and persistence in adverse environments. World J. Microbiol. Biotechnol., 33: 1-7. 